\title{
Human papillomavirus (HPV) infection and vaccination: knowledge and attitudes among healthcare professionals and the general public in Slovenia
}

\author{
Majda Troha ${ }^{\circledR}$, Anja Šterbenc ${ }^{2}$, Martina Mlaker $^{3}$, Mario Poljak²
}

\begin{abstract}
Introduction: This study evaluates knowledge of and attitudes toward human papillomavirus (HPV) infection and vaccination among healthcare professionals and the general public in Slovenia.

Methods: Five statements were designed to evaluate participants' opinions regarding age at HPV vaccine administration and potential delay in vaccination, associations of HPV vaccination with riskier sexual behavior, HPV vaccine safety, the importance of the internet as a source of information, and the significance of HPV vaccination in boys. Participants were asked to express agreement or disagreement with each statement.

Results: A total of 605 surveys were completed by medical students $(n=259)$, parents of sixth-graders in $2016(n=103)$ and 2017 ( $n=103)$, pediatricians and school medicine specialists $(n=21)$, gynecologists $(n=34)$, and women visiting gynecology outpatient clinics $(n=85)$. The highest level of knowledge and belief in the HPV vaccine and its safety was observed among pediatricians and school medicine specialists. Medical students tend to have a very positive attitude toward HPV vaccination, although they need additional education about HPV vaccine safety. Some healthcare professionals showed signs of HPV vaccine hesitancy, and their beliefs were somewhat similar to those of the general public.

Conclusions: Although the overall attitude towards HPV vaccination is generally positive, additional education must be provided to both healthcare professionals and the general public in order to achieve higher HPV vaccination coverage rates in Slovenia.
\end{abstract}

Keywords: HPV vaccination, knowledge and attitudes, healthcare professionals, general public, Slovenia

Received: 13 February 2018 | Returned for modification: 30 March 2018 | Accepted: 5 April 2018

\section{Introduction}

It has been over 40 years since Harald zur Hausen published his first report on attempts to detect human papillomavirus (HPV) DNA in cervical cancer and genital wart biopsies (1). Since then, it has unequivocally been established that HPVs are important carcinogens in humans, causing not only cervical cancer but also a significant proportion of penile, vulvar, vaginal, anal, and oropharyngeal cancers (2). Moreover, infection with HPV has proven to be the most common viral sexually transmitted disease, with an estimated global incidence of anogenital warts ranging from 160 to 289 cases per 100,000 person-years (3). Hence, prevention of HPV infections and HPV-related neoplasms has become a priority. Quadrivalent vaccine against HPV-6, HPV-11, HPV-16, and HPV-18 became the first prophylactic HPV vaccine to be registered in Europe in September 2006, followed by a bivalent vaccine against HPV-16 and HPV-18 1 year later, and a nonavalent vaccine against HPV-6, HPV-11, HPV-16, HPV-18, HPV-31, HPV-33, HPV-45, HPV-52, and HPV-58 in 2015 (4-6).

In Slovenia, HPV vaccination became the first non-mandatory vaccine to be included in the national vaccination program in the 2009/2010 school year. HPV vaccination is recommended for girls in the sixth grade (11- to 12-year-olds), whereas boys are not included in the program $(7,8)$. HPV vaccination is offered to girls free of charge as a part of a preventive care visit at primary healthcare centers. Each school selects a school medicine specialist or a pediatrician to provide preventive and immunization programs for all children in a particular school. As demonstrated in other countries, school-based vaccination is a very successful strategy to achieve high vaccination coverage rates (9).

Slovenia initially used the quadrivalent vaccine, which was switched to the nonavalent vaccine in 2016. Although HPV vaccination for girls is fully state-funded, national vaccine coverage is only around 50\%. There are significant differences in HPV vaccine uptake among different regions in Slovenia, ranging from very high (79.0\% in Ravne) to very low (32.2\% in Kranj) (10). Moreover, HPV vaccine coverage varies significantly not only at the regional level but also among different municipalities within the same region. Hence, we believe that the HPV vaccine coverage is largely influenced by the knowledge of and attitudes toward HPV infections among school medicine specialists or pediatricians that provide the immunization program at a particular school.

This study evaluated the range of concerns among various groups of healthcare professionals and the general public regarding the timing of HPV vaccination, its safety and adverse effects, the impact of HPV vaccination on sexual behavior, and the importance of vaccinating boys.

\section{Methods}

The study was designed to obtain information about the knowledge of and attitudes toward HPV infection and vaccination among various healthcare professionals and the general public. For participants that attended lectures on HPV infection and vaccination, the survey was administered prior to the lecture(s) in order to obtain independent data about their knowledge and beliefs. The survey consisted of five statements. The first statement was designed to evaluate participants' opinions regarding age at 
vaccination and potential delay in HPV vaccination. The purpose of the second statement was to evaluate whether participants associate HPV vaccination with riskier sexual behavior. The third statement evaluated participants' perspective regarding potential adverse effects of the vaccine and the relatively short period of vaccine availability on the market, and the fourth statement was designed to assess the importance of information obtained from the internet. The last statement was designed to obtain insight into participants' attitudes towards HPV vaccination in males. Participants were asked to simply mark "yes" or "no" if they agreed or disagreed with the statement.

The first group consisted of medical students at the universities of Ljubljana and Maribor in their final years that attended the first medical student conference on reproductive health (Cervical Cancer: From A to HPV), held in Ljubljana in April 2016. The second group consisted of school medicine specialists and pediatricians, who were asked to complete the questionnaires during their annual update meeting on HPV vaccination, held in September 2016 in Ljubljana. The third group consisted of gynecologists working at primary health centers that attended the Eighth Contraception Symposium, which was held in September 2017 in Ljubljana. All of these healthcare professionals should be familiar with the burden of HPV-related disease because they are supposed to deliver clear recommendations for HPV vaccination to parents and adolescents. The fourth group included parents of sixth-grade children in several small municipalities (Idrija, Cerkno, Radenci, Gornja Radgona, Apače, and Sveti Jurij ob Ščavnici). The questionnaires were administered to parents at parent-school meetings in 2016 and 2017, and the data were analyzed separately for each year. The final group consisted of women that visited their gynecologists at primary health centers in Idrija, Radenci, and Ljubljana in 2017.
No personal or demographic data were collected during the survey. Potential differences between each group were evaluated using a $x^{2}$ test, with $p$ values of $<0.05$ considered to be statistically significant. Analyses were performed using R software version 3.1.3 (Free Software Foundation, Boston, MA, USA).

\section{Results}

A total of 605 surveys were completed by medical students ( $n=$ 259), parents of sixth-graders in $2016(n=103)$ and $2017(n=103)$, pediatricians and school medicine specialists $(n=21)$, gynecologists $(n=34)$, and women visiting gynecology outpatient clinics $(n=85)$ (Table 1).

As shown in Table 1, participants with some medical training acknowledged the importance of vaccination of girls 11 to 12 years old, with the majority of medical students (94.2\%) agreeing with the first statement provided, followed by pediatricians and school medicine specialists ( $85.7 \%)$, and gynecologists (76.5\%). Parents of sixth-graders and women that took the survey at gynecology outpatient clinics are less likely to opt for HPV vaccination $37.0 \%$ and $54.4 \%$ of parents in 2016 and 2017, respectively, and $43.5 \%$ of women at gynecology outpatient clinics) and would rather see their children decide on their own after they grow up. In general, the answers provided by medical students and specialists statistically differed statistically significantly from those of the general public (Table 2).

Regarding the second statement, none of the groups considered HPV vaccination to be an important cause of riskier sexual behavior (Table 1). Moreover, the differences between distinct groups were small and mostly statistically insignificant (Table 2). Compared to other participants, the parents of sixth-graders were only slightly more convinced that their daughters would have few-

Table 1 | Attitudes toward HPV vaccination among medical students, pediatricians and school medicine specialists, gynecologists, parents of sixth-graders in 2016 and 2017, and women visiting gynecology outpatient clinics.

\begin{tabular}{|c|c|c|c|c|c|}
\hline \multirow[b]{2}{*}{ Statement } & \multirow[b]{2}{*}{ Groups } & \multirow[b]{2}{*}{ Total } & \multicolumn{3}{|c|}{$n(\%)$} \\
\hline & & & Agree & Disagree & No answer \\
\hline 1. There is no need to rush HPV vaccination & Medical students & 259 & $15(5.8)$ & $244(94.2)$ & 0 \\
\hline because 11 - or 12-year-old girls are still children. & Pediatricians and school medicine specialists & 21 & $3(14.3)$ & $18(85.7)$ & 0 \\
\hline \multirow{4}{*}{$\begin{array}{l}\text { They should decide for themselves when they are } \\
\text { older. }\end{array}$} & Gynecologists & 34 & $8(23.5)$ & $26(76.5)$ & 0 \\
\hline & Parents of sixth-graders in 2016 & 103 & $38(37.0)$ & $63(61.2)$ & $2(1.9)$ \\
\hline & Parents of sixth-graders in 2017 & 103 & $56(54.4)$ & $45(43.7)$ & $2(1.9)$ \\
\hline & Women at gynecology outpatient clinics & 85 & $37(43.5)$ & $48(56.5)$ & 0 \\
\hline 2. If girls are protected against HPV infection, & Medical students & 259 & $29(11.2)$ & $230(88.8)$ & 0 \\
\hline which is a sexually transmitted infection, they & Pediatricians and school medicine specialists & 21 & $1(4.8)$ & $20(95.2)$ & 0 \\
\hline \multirow[t]{4}{*}{ will more likely engage in risky sexual behaviors. } & Gynecologists & 34 & $5(14.7)$ & $28(82.4)$ & $1(2.9)$ \\
\hline & Parents of sixth-graders in 2016 & 103 & $18(17.5)$ & $82(79.6)$ & $3(2.9)$ \\
\hline & Parents of sixth-graders in 2017 & 103 & $28(27.2)$ & $76(71.8)$ & $1(1.0)$ \\
\hline & Women at gynecology outpatient clinics & 85 & $18(21.2)$ & $67(78.8)$ & 0 \\
\hline 3. HPV vaccine adverse effects may appear later & Medical students & 259 & $156(60.2)$ & $101(39.0)$ & $2(0.8)$ \\
\hline on because the HPV vaccine has only been avail- & Pediatricians and school medicine specialists & 21 & $1(4.8)$ & $19(90.5)$ & $1(4.8)$ \\
\hline able on the market for a relatively short period of & Gynecologists & 34 & $15(44.1)$ & $19(55.9)$ & 0 \\
\hline time and it has been included in the vaccination & Parents of sixth-graders in 2016 & 103 & $81(78.6)$ & $20(19.4)$ & $2(1.9)$ \\
\hline \multirow[t]{2}{*}{ program only since 2009.} & Parents of sixth-graders in 2017 & 103 & $79(76.7)$ & $23(22.3)$ & $1(1.0)$ \\
\hline & Women at gynecology outpatient clinics & 85 & $58(68.2)$ & $25(29.4)$ & $2(2.4)$ \\
\hline 4. Because HPV vaccination is not obligatory, par- & Medical students & 259 & $202(78.0)$ & $54(20.8)$ & $3(1.2)$ \\
\hline ents decide whether to vaccinate their daughters. & Pediatricians and school medicine specialists & 21 & $5(23.8)$ & $13(61.9)$ & $3(14.3)$ \\
\hline \multirow{4}{*}{$\begin{array}{l}\text { Their decision is mostly influenced by information } \\
\text { obtained on the internet. }\end{array}$} & Gynecologists & 34 & $19(55.9)$ & $14(41.2)$ & $1(2.9)$ \\
\hline & Parents of sixth-graders in 2016 & 103 & $51(50.0)$ & $50(48.5)$ & $2(1.9)$ \\
\hline & Parents of sixth-graders in 2017 & 103 & $54(52.4)$ & $46(44.7)$ & $3(2.9)$ \\
\hline & Women at gynecology outpatient clinics & 85 & $56(65.9)$ & $28(32.9)$ & $1(1.2)$ \\
\hline 5. HPV vaccine is primarily intended to protect & Medical students & 259 & $46(17.8)$ & 212 (81.9) & $1(0.4)$ \\
\hline women against developing cervical cancer, but it & Pediatricians and school medicine specialists & 21 & 0 & $21(100.0)$ & 0 \\
\hline also protects men against anal cancer. Because & Gynecologists & 34 & $7(20.6)$ & $27(79.4)$ & 0 \\
\hline the incidence of anal cancer is relatively low, the & Parents of sixth-graders in 2016 & 103 & $50(48.5)$ & $51(50.0)$ & $2(1.9)$ \\
\hline \multirow[t]{2}{*}{ utility of HPV vaccination in males is questionable. } & Parents of sixth-graders in 2017 & 103 & $69(67.0)$ & $31(30.1)$ & $3(2.9)$ \\
\hline & Women at gynecology outpatient clinics & 85 & $46(54.1)$ & $35(41.2)$ & $4(4.7)$ \\
\hline
\end{tabular}


er inhibitions towards early initiation of sexual intercourse and changing sex partners if they received the HPV vaccine $(17.5 \%$ and $27.2 \%$ of parents in 2016 and 2017, respectively). Pediatricians and school medicine specialists $(4.8 \%)$ that vaccinate the targeted population, as well as medical students $(11.2 \%)$, who are closer to this population in terms of age, were least likely to associate HPV vaccination with riskier sexual behavior.

Pediatricians and school medicine specialists are well acquainted with the safety of HPV vaccination, whereas a significant proportion of gynecologists (44.1\%) showed some hesitation about unknown adverse effects (Table 1). In contrast, parents of sixthgraders ( $78.6 \%$ in 2016 and $76.7 \%$ in 2017), women at gynecology outpatient clinics $(68.2 \%)$, and medical students $(60.2 \%)$ were mostly convinced that adverse effects will surface in the future because HPV vaccination has only been present in Europe since 2006. The answers provided by pediatricians and school medicine specialists regarding the safety of the HPV vaccine differed statistically significantly not only from the beliefs of the general public but also from other healthcare professionals' beliefs (Table 2).

The majority of medical students $(78.0 \%)$ believe that information regarding HPV vaccination is mostly available on the internet, which is the main source of information based on which parents decide whether to vaccinate. Similarly, parents of sixth-graders (50.0\% in 2016 and 52.4\% in 2017), women that completed the survey at gynecology outpatient clinics (65.9\%), and gynecologists $(55.9 \%)$ also believed that the internet is an important source of information on HPV vaccination (Table 1). In contrast, according to most pediatricians and school medicine specialists (61.9\%), parents do not obtain information regarding HPV vaccination from the internet. The answers provided by medical students, pediatricians, and school medicine specialists differed statistically significantly from the other groups studied, whereas gynecologists, parents of sixth-graders, and women visiting gynecology outpatient clinics tended to express similar beliefs (Table 2).

As shown in Table 1, pediatricians and school medicine specialists universally support gender-neutral HPV vaccination (Table 1). This is also true for the majority of medical students $(81.9 \%)$ and gynecologists (79.4\%). In contrast, only 50.0\%, 30.1\%, and $41.2 \%$ of parents of sixth-graders in 2016 and 2017, and women that took the survey at gynecology outpatient clinics, respectively, disagreed that HPV vaccination would not be beneficial for boys. The answers provided by healthcare professionals regarding this issue differed statistically significantly from those of the general public (Table 2).

\section{Discussion}

This study was designed to obtain information about the knowledge of and attitudes toward HPV infection and vaccination among various healthcare professionals that vaccinate adolescents and/or are consulted regarding their opinion on HPV vaccination. In addition, the survey was also administered to parents of sixth-graders in elementary school that are faced with the decision whether to vaccinate their children, and to woman visiting certain gynecology outpatient clinics that should be aware of the fact that HPV is found in virtually all cases of cervical cancer and that cervical cancer only exceptionally develops in the absence of the persistent presence of HPV (11).

The first statement evaluated participants' opinions regarding age at vaccination and potential delay in HPV vaccination. It has clearly been established that HPV vaccines are most effective when administered before exposure to HPV. The recommendation for routine vaccination at age 11 or 12 is based on several considerations, including data on HPV epidemiology and age of sexual debut as well as studies indicating that HPV vaccines are safe and highly immunogenic in this age group, with higher antibody levels achieved after vaccination at age 11 or 12 compared with older age groups (12). Moreover, findings from the Health Behaviour in School-Aged Children (HBSC) survey in 2013-14 showed that $20 \%$ of 15 -year-olds ( $23 \%$ of girls and $17 \%$ of boys) in Slovenia have already had sexual intercourse (13). Hence, intentional delay in HPV vaccination may lead to reduced efficacy of the vaccine because older individuals may have already acquired HPV infection(s). In this study, healthcare professionals generally did not support postponing HPV vaccination, whereas a significant proportion of parents of sixth-graders would prefer the HPV vaccine to be administered at a later age and at their children's initiative, probably because of fear of potential side effects they have heard or read about in the media and on the internet or because they believe that their children will not engage in sexual intercourse in the near future. It is disappointing that parents are often afraid to take responsibility for HPV vaccination. Nevertheless, parents should be aware of the fact that, in their best intentions to protect their children, deciding to refuse to vaccinate is also a form of taking responsibility for their children's health-which unfortunately can be to their children's detriment.

The second statement evaluated whether participants associate HPV vaccination with riskier sexual behavior. Specifically, one of the concerns of those that were initially against HPV vaccina-

Table 2 | Differences in knowledge of and attitudes toward HPV vaccination among the groups studied.

\begin{tabular}{|c|c|c|c|c|c|}
\hline \multirow[b]{2}{*}{ Groups } & \multicolumn{5}{|c|}{ Statement and $p$ value* } \\
\hline & 1 & 2 & 3 & 4 & 5 \\
\hline Medical students vs. pediatricians and school medicine specialists & 0.127 & 0.359 & $<0.001$ & $<0.001$ & 0.034 \\
\hline Medical students vs. gynecologists & $<0.001$ & 0.505 & 0.065 & 0.007 & 0.695 \\
\hline Medical students vs. parents of sixth-graders in 2016 & $<0.001$ & 0.087 & $<0.001$ & $<0.001$ & $<0.001$ \\
\hline Medical students vs. parents of sixth-graders in 2017 & $<0.001$ & $<0.001$ & 0.003 & $<0.001$ & $<0.001$ \\
\hline Medical students vs. women at gynecology outpatient clinics & $<0.001$ & $<0.001$ & 0.132 & 0.023 & $<0.001$ \\
\hline Pediatricians and school medicine specialists vs. gynecologists & 0.405 & 0.236 & 0.002 & 0.042 & 0.026 \\
\hline Pediatricians and school medicine specialists vs. parents of sixth-graders in 2016 & 0.039 & 0.130 & $<0.001$ & 0.075 & $<0.001$ \\
\hline Pediatricians and school medicine specialists vs. parents of sixth-graders in 2017 & 0.001 & 0.028 & $<0.001$ & 0.041 & $<0.001$ \\
\hline Pediatricians and school medicine specialists vs. women at gynecology outpatient clinics & 0.013 & 0.079 & $<0.001$ & 0.002 & $<0.001$ \\
\hline Gynecologists vs. parents of sixth-graders in 2016 & 0.134 & 0.708 & $<0.001$ & 0.480 & 0.003 \\
\hline Gynecologists vs. parents of sixth-graders in 2017 & 0.001 & 0.168 & $<0.001$ & 0.720 & $<0.001$ \\
\hline Gynecologists vs. women at gynecology outpatient clinics & 0.042 & 0.458 & 0.009 & 0.356 & $<0.001$ \\
\hline Parents of sixth-graders in 2016 vs. parents of sixth-graders in 2017 & 0.011 & 0.127 & 0.175 & 0.619 & 0.005 \\
\hline Parents of sixth-graders in 2016 vs. women at gynecology outpatient clinics & 0.105 & 0.587 & 0.105 & 0.027 & 0.328 \\
\hline Parents of sixth-graders in 2017 vs. women at gynecology outpatient clinics & 0.756 & 0.360 & 0.243 & 0.081 & 0.090 \\
\hline
\end{tabular}

* Statistical analysis was performed using a $x^{2}$ test.

Statistically significant differences with $p<0.05$ are in boldface. 
tion at age 11 or 12 was the fear that HPV vaccination of young girls would lead to sexual disinhibition because of a perceived reduction of the risk of infection. However, several studies showed no measurable differences in sexual behavior, number of acquired sexually transmitted infections other than HPV, and age of first pregnancy when comparing vaccinated girls to unvaccinated ones $(14,15)$. Although none of the groups evaluated in this study identified HPV vaccination as a cause of riskier sexual behavior, parents should be further reassured that HPV vaccination at ages 9 to 12 does not equate with encouraging early onset of sexual activity or result in an increased number of sexual partners.

The third statement was used to establish whether the HPV vaccine is regarded as safe. The Global Advisory Committee on Vaccine Safety (GACVS) is an independent expert clinical and research advisory body that has been meticulously reviewing the safety data for HPV vaccines. Based on multiple large and highquality safety studies that were carried out on several million vaccinated individuals, the GACVS concluded that HPV vaccines are extremely safe (16). Since its introduction into the Slovenian vaccination program in 2009, we have mostly noticed mild adverse events following HPV vaccination, including injection-site pain, swelling, redness, nausea, headache, fever, fatigue, and syncope. The majority of these symptoms and signs resolved within days without any long-term consequences. To date, no serious adverse events such as anaphylaxis have been reported in Slovenia (17). Although these data are freely available and are also repeatedly presented at various medical conferences, it does not seem that the general public or even some healthcare professionals perceive them as a proof of HPV vaccine safety. Namely, this study has shown that, compared to the general public and other healthcare professionals, pediatricians and school medicine specialists were the only group that showed strong belief in the safety of the HPV vaccine. Thus, the general public and healthcare professionals need to be continuously reminded that the risk of developing cervical and other HPV-related cancers far outweighs any potential risks of adverse events of HPV vaccine.

The fourth statement evaluated the significance of the internet as a source of information on HPV vaccines and vaccination. A recent study has shown that young Italian males used the mass media (47.3\%), school (26.7\%), and physicians (18.6\%) as the most common information resource for the HPV vaccine (18). In contrast, providers' recommendations have been found to be one of the most important factors in parents' decision to vaccinate their daughter(s) in other studies $(19,20)$. In this study, pediatricians and school medicine specialists did not identify the internet as the main source of information regarding HPV vaccination for parents, whereas more than half of parents of sixth-graders and the majority of medical students thought that the decision to vaccinate against HPV is mostly influenced by information obtained on the internet. It is possible that pediatricians' and school medicine specialists' beliefs are based on their own experiences; it has previously been shown that medical publications were the main source of information about HPV for personal education of Turkish physicians, whereas the media or the internet were used less often (21). Our results differ somewhat from the findings of a recent Slovenian cross-sectional study in which mothers of children included in the national vaccination program considered physicians $(85 \%)$ and nurses (74\%) to be the most trustworthy sources of information regarding vaccination, whereas $58 \%, 10 \%$, and $9 \%$ of mothers trusted information regarding vaccination obtained on websites, internet forums, and social media, respectively (22). All sources of information on which parents base health-related decisions for their children must be identified in order to overcome HPV vaccine-related hesitancy because the opportunity to educate them and promote the HPV vaccine may be lost if efforts focus on one source of information only. Parents should be warned about the pitfalls of relying solely on information available on the internet. Anti-vaxxers are especially active on the internet and social media, leaving parents exposed to contradictory and possibly even inaccurate information regarding the HPV vaccine $(23,24)$. Hence, physicians are strongly encouraged to provide accurate, clear, and updated information regarding HPV-related diseases and HPV vaccination, which should be available on appropriate, easily accessible, and user-friendly websites. With the rapid advances in telecommunication networks, targeted populations for HPV vaccination should be approached by physicians and epidemiologists using all available channels, including social media such as Facebook and Twitter. Most of all, these data should also be available to a broader circle of medical professionals and their colleagues.

The final statement provided insight into participants' opinions regarding HPV vaccination of boys. Although boys are currently excluded from the Slovenian national HPV vaccination recommendations, HPV vaccination was first provided to them free of charge in the 2015/2016 school year as a result of an outstanding local initiative by several pediatricians. Currently, HPV vaccination of boys is sponsored by various local communities throughout Slovenia, which have reached very high coverage rates (up to $83 \%$ in northeastern Slovenia). The majority of healthcare professionals included in our study agreed that boys would also benefit from HPV vaccination. Our results differ from a previous study, in which only $61 \%$ of Serbian gynecologists agreed that boys should also be vaccinated against HPV (25). In this study, parents of sixth-graders and women visiting gynecology outpatient clinics expressed a certain level of reservation regarding the potential benefits of also providing the HPV vaccine to boys. As shown in the US, this may partially be a result of "feminization" of the HPV vaccine, whereby, with respect to research, political, and economic factors and gender norms, women were identified as those bearing the greatest burden of HPV infections and related diseases and were thus thought to be responsible for their prevention (26).

Medical students are a group of healthcare professionals that are exposed to the most up-to-date medical practices and knowledge. This group also bears the greatest burden of HPV infections because the prevalence of these infections is greatest in the late teens and early twenties (27). In contrast to Asian countries, where several studies evaluated knowledge, attitudes, and practices regarding HPV infections and vaccination among medical students (28-31), these issues have not been thoroughly assessed among medical students in Europe. Two previous studies in Scotland and Romania $(32,33)$ have shown significant gaps in medical student' knowledge. This was somewhat surprising because a comprehensive public health information campaign accompanied the first year of HPV vaccination in Scotland (32). In Romania, the level of knowledge regarding HPV infection was significantly lower among students in the 1st year of medical school compared to 6thyear medical students, suggesting that some basic information is acquired during the program (33). In contrast, knowledge about HPV infections and the HPV vaccine among Slovenian medical students was relatively good, which is extremely important because it has previously been shown that increased awareness of 
HPV infections and vaccination among medical students is positively associated with higher vaccine uptake as well as their intention to recommend it (31). Moreover, the thought that future doctors favor HPV vaccination is especially encouraging because the fate of HPV vaccination will mostly be in their hands. However, additional course(s) on (HPV) vaccine safety should be added to the medical school curriculum because medical students were still not fully convinced that current prophylactic HPV vaccines are safe.

Unfortunately, Slovenian HPV vaccination coverage is well below the desired target. Since its introduction, HPV vaccination coverage rates have been steadily declining, from $54.9 \%$ in the $2011 / 2012$ school year to only $44 \%$ in the $2015 / 2016$ school year. The 2016/2017 school year was the first to show increased and not decreased HPV vaccine coverage rates. There are also significant differences in HPV vaccine uptake among various regions and even among different municipalities within the same region (10). These differences most likely reflect remarkable efforts by individual medical doctors, especially pediatricians and school medicine specialists, who provide HPV vaccination to the targeted population. In this study, pediatricians and school medicine specialists were the group with the highest level of knowledge of HPV infection and positive attitude towards HPV vaccination. However, due to the relatively low number of pediatricians and school medicine specialists $(n=21)$ included in this study and consequent selection bias, our findings may not necessarily apply to pediatricians and school medicine specialists in general. Moreover, because the survey was performed at an annual educational conference on HPV infections, HPV-related diseases, and vaccination, it is possible that the physicians that attended this conference were more interested in this topic and could have had a more positive baseline opinion regarding HPV vaccination. Interestingly, our results contrast with those of a previous study, in which the knowledge of Serbian pediatricians was poor although they still recommended the vaccine to parents (34). Because providers' recommendations were found to be one of the most important factors in parents' decision to vaccinate their children $(19,20,22,35)$, additional educational activities should be provided to pediatricians and school medicine specialists on how to best present HPV vaccination to parents, especially in regions with lower HPV vaccination coverage rates. Currently, lectures on HPV vaccination and disease burden for parents of sixth-graders are not uniformly held. Some physicians have even stopped giving lectures to parents because HPV vaccination coverage rates have remained low despite their best efforts. In some cases, anti-vaxxers persuaded other parents with their dubious and misleading statements on HPV vaccination to question the physician's professionalism. Moreover, some schools refuse to participate in educational activities on HPV vaccination, whereas in other areas healthcare workers are unable to hold them because they are already overwhelmed with work.

Surprisingly, the level of knowledge and trust in HPV vaccine was relatively poor among the Slovenian gynecologists that participated in the study and was similar to recent findings among Serbian gynecologists (25). Because the number of gynecologists included in our study was low $(\mathrm{n}=34)$ and due to consequent selection bias, our results may not be applicable to the majority of Slovenian gynecologists. However, the vaccine hesitations and limited knowledge among the gynecologists in this survey demand urgent action. This is especially important because mothers often seek additional advice and opinions from their gynecologist following lectures about HPV at parent-school meetings.

The knowledge of parents of sixth-graders is also considered low, with differences observed between parents of sixth-graders in 2016 and 2017. Surprisingly, the level of knowledge did not increase with time, but declined from 2016 to 2017. Unfortunately, we could not identify the proportion of parents with more than one child that attended previous lectures on HPV in each year, which could have potentially influenced their knowledge and beliefs regarding HPV infection and vaccination. Nevertheless, despite overwhelming data on HPV vaccine safety (16), it is clear that parents are still concerned about potential adverse effects of the vaccine. We believe we will be able to gradually overcome this deep-rooted fear of the HPV vaccine; however, a multilevel approach is needed with the engagement of various governmental institutions, non-medical healthcare workers, and physicians, who should set an example by having their children vaccinated against HPV.

Women visiting gynecology outpatient clinics provided answers that were similar to those of parents of sixth-graders, suggesting that their knowledge and beliefs most likely reflect those of the general Slovenian population. Personal experiences with HPV-related diseases significantly contribute to awareness and the decision to vaccinate. When women with previous HPV-related diseases attended parent-school meetings on HPV and were willing to share their experiences with others, parents almost universally decided to have their children vaccinated for HPV. In contrast, parents that oppose HPV vaccination and speak up during parental meetings may deter the entire group of parents from vaccinating their children (22). Thus, instead of listing dull scientific data that some parents may not fully understand, healthcare professionals should include personal experiences in their lectures, especially because experiences with HPV-related disease may affect parents on an emotional level and provide a strong motivation for HPV vaccination.

Our study had some limitations, the most important being selection bias. Because no personal or demographic data were collected during the survey, we could not evaluate potential differences between males and females or between younger and older medical students. In addition, age-related differences among various specialists as well as the general public could not be assessed. Moreover, because the survey was provided only prior to the lectures on HPV infections and HPV vaccines and was not repeated after the lectures, we were unable to evaluate whether providing credible research data would result in increased knowledge and a positive attitude toward HPV vaccination.

Although the final decision whether to vaccinate or not is up to parents, it is our responsibility as healthcare professionals to provide them with the necessary information on which to base the decision to vaccinate their children. 


\section{References}

1. The Nobel Assembly at Karolinska Institutet. The discoveries of human papilloma viruses that cause cervical cancer and of human immunodeficiency virus [Internet]. [cited 2018 Mar 14]. Available from: https://www.nobelprize.org/nobel_prizes/medicine/laureates/2008/advanced-medicineprize2008.pdf.

2. zur Hausen H. Papillomaviruses in the causation of human cancers-a brief historical account. Virology. 2009;384:260-5.

3. Park IU, Introcaso C, Dunne EF. Human papillomavirus and genital warts: a review of the evidence for the 2015 Centers for Disease Control and Prevention Sexually Transmitted Diseases Treatment Guidelines. Clin Infect Dis. 2015;61 Suppl 8:S849-55.

4. European Medicines Agency. EPAR summary for the public - Silgard [Internet]. London. [cited 2018 March 14]. Available from: http://www.ema.europa. eu/docs/en_GB/document_library/EPAR_-_Summary_for_the_public/human/000732/WC500051550.pdf.

5. European Medicines Agency. EPAR summary for the public - Cervarix [Internet]. London. [cited 2018 March 14]. Available from: http://www.ema.europa. eu/docs/en_GB/document_library/EPAR_-_Summary_for_the_public/human/000721/WC500024634.pdf.

6. European Medicines Agency. EPAR summary for the public - Gardasil 9 [Internet]. London. [cited 2018 March 14]. Available from: http://www.ema.europa. eu/docs/en_GB/document_library/EPAR_-_Summary_for_the_public/human/003852/WC500189114.pdf.

7. Nacionalni inštitut za javno zdravje. Program cepljenja in zaščite z zdravili za leto 2015 [Internet]. Ljubljana, Slovenia. [cited 2018 March 10]. Available from: http://www.nijz.si/sites/www.nijz.si/files/uploaded/predlog_pograma_2015_ zadnja_verzija_9.6.2015.pdf. Slovenian.

8. Nacionalni inštitut za javno zdravje. Navodila za izvajanje Programa cepljenja in zaščite z zdravili za leto 2015 [Internet]. Ljubljana, Slovenia. [cited 2018 March 10]. Available from: http://www.nijz.si/sites/www.nijz.si/files/uploaded/navodila_za_izvajanje_ip_2015_fin_za_splet_1.pdf. Slovenian.

9. Skinner SR, Robbins SCC. Voluntary school-based human papillomavirus vaccination: an efficient and acceptable model for achieving high vaccine coverage in adolescents. J Adolesc Heal. 2010;47:215-8.

10. Nacionalni inštitut za javno zdravje. Analiza izvajanja cepljenja v Sloveniji v letu 2016 [Internet]. Ljubljana, Slovenia. [cited 2018 May 10]. Available from: www. nijz.si/sites/www.nijz.si/files/uploaded/porocilo_cepljenje2016.pdf. Slovenian.

11. Schiffman M, Castle PE, Jeronimo J, Rodriguez AC, Wacholder S. Human papillomavirus and cervical cancer. Lancet. 2007;370:890-907.

12. Markowitz LE, Dunne EF, Saraiya M, Chesson HW, Curtis CR, Gee J, et al. Human papillomavirus vaccination: recommendations of the Advisory Committee on Immunization Practices (ACIP). MMWR Recomm Rep. 2014;63:1-30.

13. WHO. Growing up unequal: gender and socioeconomic differences in young people's health and well-being [Internet]. Geneva. [cited 2018 February 26]. Available from: http://www.euro.who.int/_data/assets/pdf_file/0003/303438/ HSBC-No.7-Growing-up-unequal-Full-Report.pdf?ua=1.

14. Bednarczyk RA, Davis R, Ault K, Orenstein W, Omer SB. Sexual activity-related outcomes after human papillomavirus vaccination of 11- to 12-year-olds. Pediatrics. 2012;130:798-805.

15. Hansen BT, Kjær SK, Arnheim-Dahlström L, Liaw KL, Jensen KE, Thomsen LT, et al. Human papillomavirus (HPV) vaccination and subsequent sexual behaviour: evidence from a large survey of Nordic women. Vaccine. 2014;32:4945-53.

16. Meeting of the Global Advisory Committee on Vaccine Safety, 7-8 June 2017. Wkly Epidemiol Rec. 2017;92:393-402.

17. Nacionalni inštitut za javno zdravje. Neželeni učinki pridruženi cepljenju v Sloveniji v letu 2016. Ljubljana, Slovenia. [cited 2018 February 27]. Available from: http://www.nijz.si/sites/www.nijz.si/files/uploaded/porocilo_nu2016_1. pdf. Slovenian.
18. Napolitano F, Napolitano P, Liguori G, Angelillo IF. Human papillomavirus infection and vaccination: knowledge and attitudes among young males in Italy. Hum Vaccin Immunother. 2016;12:1504-10.

19. Gamble HL, Klosky JL, Parra GR, Randolph ME. Factors influencing familial decision-making regarding human papillomavirus vaccination. J Pediatr Psychol. 2010;35:704-15.

20. Zimet GD. Health care professionals and adolescent vaccination: a call for intervention research. Hum Vaccines Immunother. 2014;10:2629-30.

21. Naki MM, Celik H, Api O, Toprak S, Ozerden E, Unal O. Awareness, knowledge and attitudes related to HPV infection and vaccine among non-obstetriciangynecologist healthcare providers. J Turk Ger Gynecol Assoc. 2010;11:16-21.

22. Nacionalni inštitut za javno zdravje. Cepljenje: stališča in odnos ključnih javnosti do cepljenja v Sloveniji. Ljubljana, Slovenia. [cited 2018 May 2]. Available from: http://www.nijz.si/sites/www.nijz.si/files/publikacije-datoteke/monografija_8_07-03-18.pdf. Slovenian.

23. Madden K, Nan X, Briones R, Waks L. Sorting through search results: a content analysis of HPV vaccine information online. Vaccine. 2012;30:3741-6.

24. Patel PR, Berenson AB. Sources of HPV vaccine hesitancy in parents. Hum Vaccin Immunother. 2013;9:2649-53.

25. Stamenkovic Z, Matejic B, Djikanovic B, Zaric M. Gynecologists' knowledge, attitudes, and intentions toward human papillomavirus vaccination in Serbia. J Low Genit Tract Dis. 2017;21:9-11.

26. Daley EM, Vamos CA, Thompson EL, Zimet GD, Rosberger Z, Merrell L, Kline NS. The feminization of HPV: how science, politics, economics and gender norms shaped U.S. HPV vaccine implementation. Papillomavirus Res. 2017;3:142-8.

27. Smith JS, Melendy A, Rana RK, Pimenta JM. Age-specific prevalence of infection with human papillomavirus in females: a global review. J Adolesc Health. 2008;43:S5-25, S25.e1-41.

28. Fu CJ, Pan XF, Zhao ZM, Saheb-Kashaf M, Chen F, Wen Y, et al. Knowledge, perceptions and acceptability of HPV vaccination among medical students in Chongqing, China. Asian Pac J Cancer Prev. 2014;15:6187-93.

29. Swarnapriya K, Kavitha D, Reddy GM. Knowledge, attitude and practices regarding HPV vaccination among medical and para medical in students, India a cross sectional study. Asian Pac J Cancer Prev. 2015;16:8473-7.

30. Yam PWA, Lam PL, Chan TK, Chau KW, Hsu ML, Lim YM, et al. A cross sectional study on knowledge, attitude and practice related to human papillomavirus vaccination for cervical cancer prevention between medical and non-medical students in Hong Kong. Asian Pac J Cancer Prev. 2017;18:1689-95.

31. Liu A, Ho FK, Chan LK, Ng JY, Li SL, Chan GC, et al. Chinese medical students' knowledge, attitude and practice towards human papillomavirus vaccination and their intention to recommend the vaccine. J Paediatr Child Health. 2018;54: 302-10.

32. McCusker SM, Macqueen I, Lough G, Macdonald Al, Campbell C, Graham SV. Gaps in detailed knowledge of human papillomavirus (HPV) and the HPV vaccine among medical students in Scotland. BMC Public Health. 2013;13:264.

33. Voidăzan S, Morariu SH, Tarcea M, Moldovan H, Curticăpian I, Dobreanu M. Human papillomavirus (HPV) infection and HPV vaccination: assessing the level of knowledge among students of the University of Medicine and Pharmacy of Tîrgu Mureş, Romania. Acta Dermatovenerol Croat. 2016;24:193-202.

34. Nikolic Z, Matejic B, Kesic V, Eric Marinkovic J, Jovic Vranes A. Factors influencing the recommendation of the human papillomavirus vaccine by Serbian pediatricians. J Pediatr Adolesc Gynecol. 2015;28:12-8.

35. Gargano LM, Herbert NL, Painter JE, Sales JM, Morfaw C, Rask K, et al. Impact of a physician recommendation and parental immunization attitudes on receipt or intention to receive adolescent vaccines. Hum Vaccin Immunother. 2013;10: 2627-33. 